\title{
A production planning in highly automated manufacturing system considering multiple process plans with different energy requirements
}

\author{
Yong-Chan Choi • Paul Xirouchakis
}

Received: 27 March 2013 / Accepted: 9 September 2013 /Published online: 5 October 2013

(C) Springer-Verlag London 2013

\begin{abstract}
This paper focuses on a production planning problem in a highly automated manufacturing system considering multiple process plans with different energy requirements. The system consists of several closely interconnected sub-systems such as the processing system, the material (part) handling system, the tool transport system and the auxiliary system responsible for a supply of cooling/lubricants and a waste disposal. We propose a methodology for an estimation of energy consumption and material flows that are incurred at a system level with respect to multiple process plans for a part type. In addition, this study focuses on a production planning problem with the objective to minimize the weighted sum of energy consumption, inventory holding cost and backorder cost on a FMS considering multiple process plans. The production planning model is developed as a linear programming model. The benefit coming from the adoption of suggested model has been addressed with reference to a real industrial use case study.
\end{abstract}

Keywords Production planning $\cdot$ Flexible manufacturing system $\cdot$ Minimum energy consumption $\cdot$ Multiple process plans

\section{Introduction}

Industry is one of the largest energy consumers, accounting for more than one third of primary energy consumption worldwide [25]. Today, the higher energy cost, the increasing energy demand and the growing concern over global warming, have

Y.-C. Choi $(\bowtie) \cdot$ P. Xirouchakis

Institute of Mechanical Engineering, Swiss Federal of Technology

Lausanne (EPFL), STI-IGM-LICP, Station 9, ME A1,

1015 Lausanne, Switzerland

e-mail: yongchan.choi@epfl.ch resulted in greater efforts toward the minimization of energy consumption. The necessity for the manufacturing system to consider less energy and resource consumption (and related environmental impact) emerges as an essential challenge for industrial sector.

Potential for energy saving in manufacturing lies not only in continuously increasing the energy efficiency of production processes, logistics, buildings and products' life cycle, but also in developing novel energy monitoring and management approaches [12]. Holistic approach for designing machine tools and production system with the concept of dematerialization is considered [8]. Recently, low energy availability, high prices and knowledge on the system's energy consumption structure are the main reasons for necessity of a new measure in planning and operating production systems.

This paper focuses on the production planning problem in highly automated manufacturing system considering multiple process plans with different energy requirements. The sysem consists of several closely interconnected subsystems with diverse influencing factors such as the processing system, the material (part) handling system and the tool supply system. In addition, it comprises special logistic systems (such as the auxiliary system) responsible for the supply of cooling/ lubricants and the waste disposal. FMS (flexible manufacturing system) is a well-known automated manufacturing system. All involved power-driven technical equipments related to the system contribute to the total energy consumption profile of the system.

The total energy consumption is a sum of the following components, namely energy for a part machining, a material (part) handling and a tool transport. Another contributor to this total sum is the energy for cutting chip transport and fluid transport by various auxiliary systems which will be considered whenever a specific system configuration includes such equipments. The components for energy consumption required by a process plan/a part are estimated as shown in 
Fig. 1. In addition, material flows such as the volumes of cutting chips removed and chip fluid consumed are estimated.

In general, a process plan specifies technological feasible instructions describing how to make a part. Basically, it's a recipe. The multiple process plans, an extension of a single process plan, specify alternative operations, their sequence, and alternative machines for each operation [10]. The alternative process plans are also defined in identifying alternative setup planning and pallet configurations $[8,20]$. The alternative process plans for a specific part have a different effect on the energy consumption profile due to those different manufacturing specifications.

Nowadays, consideration of only traditional economical performance criteria (cost, throughput, time, quality, etc.) in the evaluation of a production system has not been satisfied. The holistic tool to be developed for a evaluation for various production plans is required at getting the ouput with a minimum energy consumption from the amount of resources ready for use. In addition, the assessment for energy consumption in terms of multiple process plans is strongly required. This study focuses on a production planning problem with the objective to minimize the weighted sum of energy consumption, inventory holding cost and backorder cost on a FMS considering multiple process plans with different energy requirements.

Research on production planning problems with the objective of minimizing total energy consumption on a FMS considering multiple process plans is very rare. However, there have been research articles on other production planning problems related to the problem considered in this paper, such as the problems with objective of minimizing total cost (or total cost including energy cost) and on other energy consumption assessment problems, such as the energy assessment problems for the machine tool system and conveyor systems. Also, most of the studies consider scheduling and planning problems with multiple process plans, but not much progress has been made for the problems with the assessment for energy consumption related to multiple process plans.

There are a number of studies on linear programming models for a production planning problem. A typical LP planning model has the objective of minimizing the total cost (generally covering the production cost, inventory cost, shortage cost, etc.) The usual constraints are inventory balances, production quantity, demand quantity and capacity constrains over the planning horizon $[1,6,13,22]$. Bang and Kim [4] develop a LP production planning model with the objective for minimizing the weighed sum of production cost, inventory costs (including WIP inventory) and backorder cost, respectively.

There are research articles in production planning model with objective of minimizing the total cost including optimum energy cost (energy flows, machining energy and so on). Mitra et al. [16] consider a deterministic MILP model for the optimal operational production planning for continuous power-

Process Plan $j /$ Part $i$

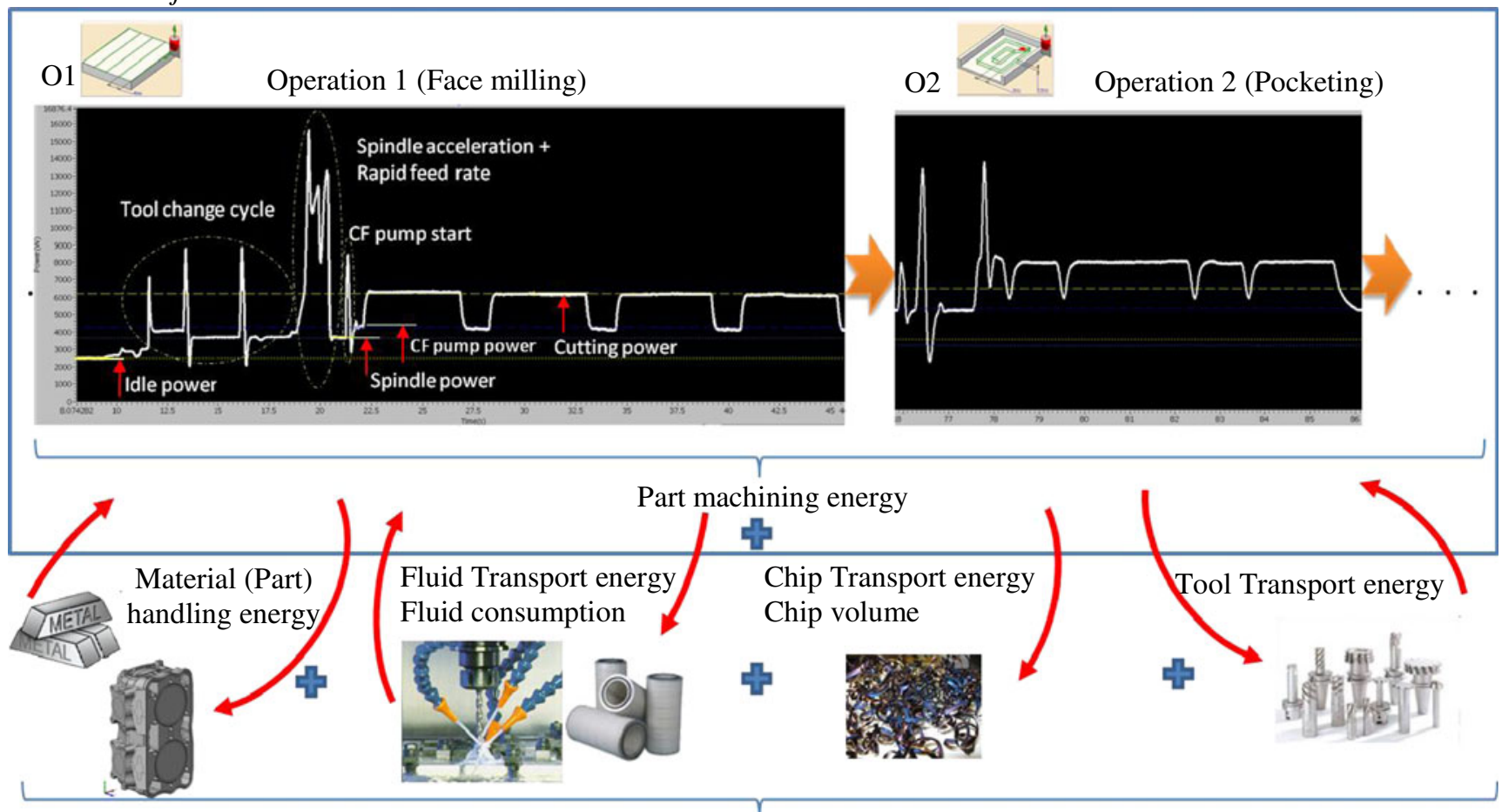

Part embodied energy

Fig. 1 Energy consumption and material flows 
intensive processes in cement plants. Bettoni and Zanoni [5] focus on the energy efficiency effects of production planning decisions in the die casting processes with the aim to minimize the energy necessary to satisfy the demands of finished products.

On the other hands, there are research articles on energy consumption in production scheduling problems. Mouzon et al. [18] and Yildirim and Mouzon [27] consider a scheduling problem to minimize the total completion time and energy consumption. Mouzon and Yildirim [17] propose a new meta heuristic to minimize total energy consumption and total tardiness on a single machine. Zhang et al. [28] propose an approach with the scheduling problem in FMS, taking the objectives of minimum energy consumption or maximum energy consumption into account.

For problems on estimation for energy consumption in manufacturing system, Cannata et al. [7] present a procedure for the energy/emission analysis of production processes in discrete manufacturing. Seow and Rahimifard [23] propose a framework for modeling energy consumption within manufacturing systems. Weinert et al. [25] describe a methodology for energy consumption prediction based on describing the energy consumption of production equipment e.g., machining centres or handling and transport systems according to operating states. Weinert et al. [26] demonstrate the suggested methodology in production processes of a generator plant.

For problems on energy consumption and environmental impacts for machining in a machine tool system, Dahmus and Gutowski [9] consider not only the environmental impact of the material removal process itself, but also the impact of associated processes such as material preparation and cutting fluid preparation. Avram and Xirouchakis [3] propose an analytical approach for the estimation of the variable mechanical energy requirements of a machine tool system with experimental verification. Avram et al. [2] propose a method for sustainability assessment of the use phase of machine tool systems considering economy, technology and ecology. Also, there are research articles on energy flows of material handling systems such as a screw conveyor and a belt conveyor. Soavi and Zurla [24] carry out performance evaluation of a new screw conveyor for metal swarf. Marx [15] suggests an energy audit methodology for belt conveyors. Zhang and Xia [29] propose a new energy calculation model of a belt conveyor.

There are research articles on scheduling problem and production planning problem with multiple process plans. Ozguven et al. [19] develope a mixed integer programming model for job shop scheduling that minimizes makespan. Rajabinasab and Mansour [21] suggest an agent-based approach in dynamic flexible job shop scheduling with alternative process plans. Doh et al. [10] consider the job shop scheduling problem with alternative operations and machines, called the flexible job shop scheduling problem. Albey and Bilge [1] propose the LP model considering alternative process routes in production planning problem to minimize the production, holding and backorder costs. On the other hand, Jiang et al. [11] develop an environmental performance assessment method for a manufacturing process plan.

In this paper, we focus on a production planning problem in highly automated manufacturing system considering multiple process plans with different energy requirements. In the next section, we describe the energy consumption and material flows estimation model with respect to multiple process plans for a part. Section 3 presents the linear programming formulation for the production planning problem in considered system. Based on an industrial use case study, performance of the proposed models is evaluated with a series of tests and results are reported in Section 4. Finally, Section 5 concludes the paper with a short summary and discussions on possible extensions.

\section{Energy and material flows estimation model}

The proposed estimation model is based on a process plan viewpoint with the aim of representing the amount of energy attributed to the manufacture of a unit product. Depending on the manufacturing process, process parameters and the system configuration, the energy flow and material flows are estimated with respect to multiple process plans for each part type.

\subsection{Energy flows estimation}

The energy consumed by various activities from all involved power driven resources during the machining of one part is categorized as part machining energy, material (part) handling energy, chip transport energy and tool transport energy as shown in Fig. 1. The energy delivered by electric utilities expressed in kilowatt hour $(k W h)$ is typically used. However, due to the fact that the processes analyzed are at most in the range of a few minutes, it is more convenient to express all the energy related values in kilojoules $(k J)$. If we measure the power for power driven-resources, the consumed energy $(k J)$ is a simple product between the measured power value $(\mathrm{kW})$ and processing time (second).

\subsubsection{Part machining energy}

Basically, every machine tool needs a specific time to start (ramp-up time) before reaching the ready-to-machine state. The amount of energy consumed during this time is very specific to each machine type. However, from the production planning perspective, we neglect the ramp-up time and we start from the premise that the machine is in the idle state waiting to start the processing of the part. There are various variables influencing the actual machining energy consumption such as the type of manufacturing process, process 
parameters and the structure/components and control of the specific machine tool.

The processing system consists of machine tools provided with local tool exchange and tool storage systems, internal chip conveyors and cutting fluid recirculation systems. The part machining energy can be estimated on a basis of different use modes of the machine tool and their respective time share in the covered time span (idle, setup, runtime and cutting). That is to say that during the machining of a part, the machine tool changes its state which yields an alteration of the power requirements.

In the idle mode, an idle power $\left(P_{\text {idle }}\right)$ represents the power drawn constantly as long as the machine is on which, similar to the ramp-up energy, is a machine-specific value. The most accurate way to determine this value is through measurements. We mention that there are some power consuming elements (i.e. hydraulic unit) that function on an intermittent basis and their power build on top of the idle power level for a limited amount of time. Each machine requires different idle power.

During the setup mode, it is assumed that the machine is in the idle state and does not have any additional power requirements unless the machine is equipped with an automated pallet changer to perform the loading/unloading activities of the parts/pallets. If the pallet uses a hydraulic pump to clamp the parts, its power requirements $\left(P_{p c}\right)$ should be accounted for as part of the setup activities. Generally, the clamping of the parts is performed at the operator station and the pressure applied is the same regardless the number of parts mounted on the pallet.

The runtime mode addresses all the activities performed by the machine tool over the length of the part program in order to support the material removal. The following activities fall under this category: the accelerations/decelerations and steady-state running of the spindle and feed axes, the tool changes, cutting fluid pumping and removal of the chips from the machine tool area. The energy consumed by any other power-driven units that might run during the machining of the part (i.e. exhaust fan, air conditioner of the electrical cabinet, etc.) can be quantified if the corresponding average value of the miscellaneous power $\left(P_{\text {misc }}\right)$ and times are available from measurements.

Since the electrical and mechanical losses of the feed axes and spindle during steady-state (running the spindle/feed axes at the programmed speed) and transient regimes (accelerations and decelerations) are speed related (not constant values since they are specific to each process), they are not taken into account in the calculation of the part machining energy. However if power data at various speeds are available for the spindle and the axes, we can assume that through a simple linear interpolation, the steady-state power $\left(P_{\text {stead-state }}\right)$ required by an operation can be estimated.

For complex part programs requiring many tool changes, the tool-to-tool time represents a considerable part of the machining time. This is due to several activities such as movement of the axes, the tool change itself or movement of other components (i.e. rotation of the tool change arm, rotation of the tool magazine). The movements performed are closely related to the machine design. Therefore an average value of the tool change power $\left(P_{t c}\right)$ can be derived from measurements with respect to the aforementioned activities.

Generally, mechanical chip removal conveyors are built into the machine to continuously discharge the chips produced during machining into a centralized conveyor serving several machines. The screw conveyors are usually employed for the evacuation of the chips outside of the machine. Since the screw conveyors are located inside the machine being connected to its general power supply, they are treated as part of the runtime activities. Therefore it is assumed that they run continuously as long as the material is being removed from a specific part. The power $\left(P_{\text {screw }}\right)$ for the screw conveyor system can be derived from measurements. On the other hand, the chip conveyors located outside the machine are considered as part of the auxiliary system.

If the cutting fluid is used for a specific process, this is delivered by a pump for the entire time length of the process. Generally, a centralized cooling system accommodates the pumps responsible for the delivery of the cutting fluid to the cutting area of each machine. The cutting fluid delivery power $\left(P_{\text {pump }}{ }^{\text {delivery }}\right)$ with measurements can be retrieved in the corresponding powers (low pressure power or high pressure power depending on the distance between each machine and centralized cooling system). On the machine side, there is only one pump that will transfer the fluid from the tank of the machine back to the centralized system. Therefore, the power $\left(P_{\text {pump }}{ }^{\text {return }}\right)$ and the time required by the return pump should be considered in the part machining energy.

In the cutting mode, a cutting power $\left(P_{\text {cut }}\right)$ for an operation is calculated as the following formula: $P_{c u t}=\frac{F_{c} \cdot v_{c}}{60} \cdot 10^{3}$. $F_{c}(N)$ is the cutting force estimated analytically as a function of the chip geometry. $v_{c}\left(\frac{m}{\min }\right)$ is the cutting speed $=\frac{\pi \cdot D \cdot s}{1000}$.

The part machining energy is highly dependent on the amount of empirical data available for each machine tool and the processing time which is dictated by the part geometry, tool path and material removal rate. The part machining energy $E_{i j}{ }^{P M}(k J)$ consumed during the machining of one part (according to process plan $j$ dedicated to part $i$ ) can be estimated through the following formula:

$$
\begin{aligned}
E_{i j}^{P M}= & \sum_{p=1}^{n_{\text {ops }}^{j}}\left\{\left(P_{\text {idle }}+P_{\text {pump }}^{\text {delivery }}+P_{\text {cut }}+P_{\text {stead-state }}+P_{\text {screw }}\right) \cdot t_{p}\right\} \\
& +\left(P_{\text {idle }}+P_{\text {pump }}^{\text {return }}\right) \cdot t_{\text {return }}+\left(P_{\text {idle }}+P_{\text {misc }}\right) \cdot t_{\text {misc }} \\
& +n_{t c} \cdot\left(\left(P_{\text {idle }}+P_{t c}\right) \cdot t_{\text {tc }}^{j}\right)+\frac{\left(P_{\text {idle }}+P_{p c}\right) \cdot t_{\text {pallet }}}{n_{\text {pallet }}}
\end{aligned}
$$




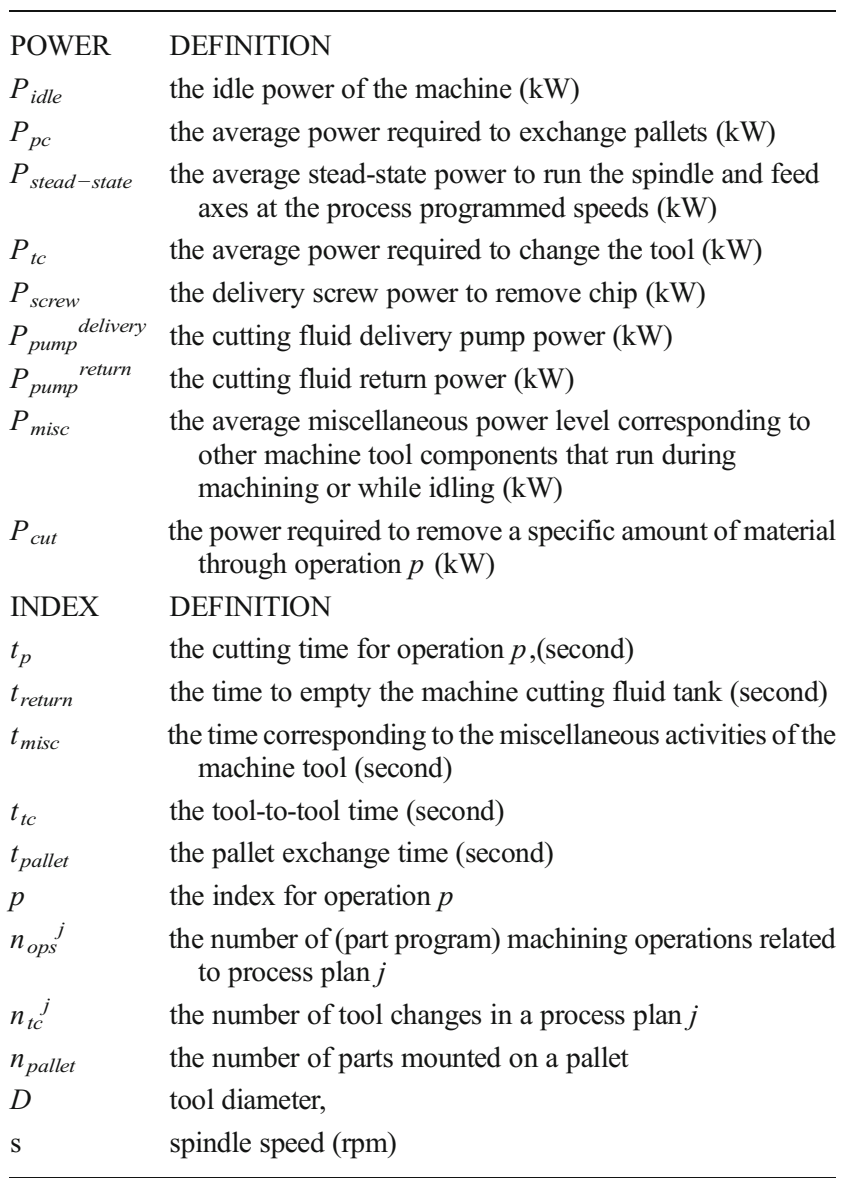

\subsubsection{Material (part) handling energy}

Material (part) handling systems are used in manufacturing and production environments to take materials from one location to another. The pallets, used as unitizing equipment to group parts of the same type, are transported from the storage to the machining area and back to storage by a conveyor, a shuttle, a robot or an AGV. From the production planning perspective, it is difficult to estimate the exact travel times or frequency between storages/retrieves. The energy $E_{i j}{ }^{M H S}(k J)$ consumed by the material (part) handling systems can be estimated by using the product between average travel time and the driving powers for the material (part) handling systems according to process plan $j$ of part $i$.

\subsubsection{Tool transport energy}

The tool transport energy $E_{i j}{ }^{\text {Tool }}(k J)$ consumed by the transportation of the tools to the machines (according to process plan $j$ for part $i$ ) from tool storage area can be achieved through a separate tool transportation system. Tool delivery includes transporting the tools to and from the machine tool requiring those tools and loading and unloading the tool magazines once the tool arrives at the machines. Tool transport energy can be estimated by considering the driving power, the speed of the tool transportation system and average travel distance between the equipments on a specific FMS configuration.

\subsubsection{Chip transport energy}

If the screw conveyors were responsible for the evacuation of the chips outside the machine area, the chain conveyors support their transport between the machines and the centralized chip container. The employment of chain conveyors is quite common for the centralized chip transport. We can assume that a FMS has one (centralized) single chain conveyor which collects the chips from all the working machines. The total capacity of the chain conveyor $Q_{c h}\left(m^{3} / h\right)$ can be estimated with the following formula: $Q_{c h}=A \cdot v_{c h} \cdot 3600$

where
$A\left(m^{2}\right)$ the product between the through width and layer height of the chain
$v_{c h} \quad$ the chain speed $(\mathrm{m} / \mathrm{s})$

The estimation of the total available capacity can be useful to check if the chain conveyor can ensure the transport of the entire amount of chips generated by the machines working simultaneously. The chip transport time $\left(t_{c h}\right)$ in the chain conveyor can be determined with $t_{c h}=\frac{d_{m}}{v_{c h}}$. The transported material flow for the screw conveyor $Q_{s c}\left(m^{3} / h\right)$ can be estimated with the following formula: $Q_{s c}=3600 \cdot \lambda \cdot \frac{\pi \cdot D^{2}}{4} \cdot \frac{s \cdot n^{r}}{60} \cdot \rho \cdot k$. The chips transport time $t_{s c}$ in the screw conveyor from a machine to the centralized chain conveyor can be approximated as: $\left.t_{s c}=L{ }_{\left(s \cdot n^{r}\right.} / 60\right)$. The power $\left(P_{c h}\right)$ required by the chain conveyor and the power $\left(P_{s c}\right)$ required by the screw conveyor can be derived from measurements.

where

$d_{m} \quad$ distance between the individual machine tool $(m)$ and the centralized chip container.

$\lambda$ the trough-filling coefficient of the conveyor (between 0.32 and 0.4 )

$s \quad$ the pitch of the screw in $\mathrm{m}$ (between 0.5 and 1 times its diameter)

$\rho \quad$ the material density in $\mathrm{kg} / \mathrm{m}^{3}$

$k \quad$ the flux material decrement coefficient (for horizontal conveyors its value is 1 )

$D$ the screw diameter in $\mathrm{m}$

$n^{r} \quad$ the screw rotating speed in rpm (for lighter materials can be considered $<150 \mathrm{rpm}$ )

$L \quad$ the length of the screw conveyor (m)

The corresponding energy $E_{i j}{ }^{C T}(k J)$ consumed for the transport of the chips generated during the machining of one part can be calculated by taking into account the ratio between the material removal rate per a part $\operatorname{MRR}_{i}\left(\mathrm{~cm}^{3} / \mathrm{min}\right)$ and 
the maximum available capacity of the screw conveyor $Q_{s c}\left(m^{3} / h\right)$ and chain conveyor $Q_{c h}\left(m^{3} / h\right)$ determined with the previous formulas. The formula below provides also the conversion factors for the two capacities (converted to the same units as the MRR):

$E_{i j}^{C T}=\operatorname{MRR} \cdot\left(\frac{P_{s c} \cdot t_{s c}}{1.66 \cdot 10^{7} \cdot \rho \cdot Q_{s c}}+\frac{P_{c h} \cdot t_{c h}}{1.66 \cdot 10^{4} \cdot Q_{c h}}\right)$

\subsubsection{Total energy consumption}

Finally, the total energy $E_{i j}{ }^{\text {Total }}(k J)$ consumed from the all power driven resources (according to process plan $j$ for part $i$ ) during the machining of one part can be estimated by taking into account the part machining energy, the chip transport energy, the material (part) handling energy and tool transport energy.

$E_{i j}^{T o t a l}=E_{i j}^{P M}+E_{i j}^{M H S}+E_{i j}^{T o o l}+E_{i j}^{C T}$

\subsection{Material flows estimation}

Two material streams are also considered in this paper: the cutting fluid consumed and the volume of chips removed. If metal chips and/or cooling lubricants are to be conveyed fully automatically from the machines to a central point, system solutions are required. The system consists of individual and centralized components closely correlated. On the machine side, we can identify screw conveyors and cutting fluid delivery pumps whereas on the system side centralized systems can serve for the collection and transport of the chips and for the filtration and movement of the cutting fluid from all the machine tools of the FMS.

After the transport of the chips and fluid has been accomplished along with the primary separation, very often the fluid needs to be further processed. This takes place by employing one or several pumps. After a specific use time, the cutting fluid must be disposed. More material removed means faster degradation of the cutting fluid characteristics which inevitably will require a change more often. Starting from this premise, we can assume that each part contributes to the degradation of the cutting fluid in a proportional way with respect to the quantity of material removed, being responsible for the disposal of a fraction of the fluid. This can be calculated as:

$f_{i}=\frac{V_{i}^{\text {chip }}}{V_{\text {Total }}^{\text {chip }}} \cdot C_{\text {Total }}^{\text {Fluid }}$

where:

$f_{i} \quad$ the fraction (liter) of the fluid disposed corresponding to the machining of the part $i$.
$V_{i}^{\text {chip }}$
the volume $\left(\mathrm{cm}^{3}\right)$ of chips removed by
machining part $i .\left(=M R R_{i}\right)$
$V_{\text {Total }}{ }^{\text {chip }}$
the total volume $\left(\mathrm{cm}^{3}\right)$ of chips removed by
machining the planned number of parts across
the fluid useful life length.
$C_{\text {Total }}^{\text {Fluid }}$
the total capacity of the centralized fluid filtration tank.

Through the above formula, the fluid flows can be estimated with respect to alternative process plans for a specific part type. On the other hand, the total material volumes removed from a raw part by following a specific process plan can be easily determined by summing the chip volumes removed over the all operations related to the part $i$. The removed chip volume is the same for one part regardless of alternative process plans employed for its machining.

\section{Production planning model}

We focus on a production planning problem on a highly automated manufacturing system considering multiple process plans with different energy effects. The multi-produt aggreaged production planning model examined here can be described as follows. Assume that a company manufactures $N$ types of products to fulfill customer demands over planning horizon $T$. Each part (product) type has multiple process plans which are defined on a basis of alternative operations, alternative machine tools and alternative pallet configurations. The completion of an individual process plan requires a specific amount of energy and fluid and also generates a specific volume of chips.

The production planning model is developed as a linear programming where the objective function can minimize the weighted sum of energy consumption, inventory holding cost and backorder cost, subject to linear constraints pertaining to various resources (machine tool, tool, pallet and auxiliary system with centralized cutting fluid system). Machine tools are the critical resources. All machine tools of the same type are regarded as a single machine resource and all tools are aggregated similarly. Pallets are also considered as critical resources. The number of parts mounted on a pallet type is different according to alternative pallet types. The cutting fluid must be disposed after a specific use time. The centralized cutting fluid system with limited capacity is considered (The fluid amount for recycling during the period $t$ is considered).

Before determining the production planning, the process planning and the system configuration should be preceded, sequentially [8]. The major works of process planning are to specify technological instructions describing how to make a product. In addition, the machinability of the pallet on the possible machine tools was already verified through process 
planning approach. A machine tool copy configuration, a pallet copy configuration and a tool copy configuration was already determined through the system configuration step. In the considered FMS, the tool movement policy is considered, where parts are assigned to machine tools and necessary tools are transported to machine tools to finish the operations [14]. Details of the problem such as batch production, reworks, scraps or machine breakdown are not considered.

We use the following index, set, parameter and decision variables in the formulation.

\section{$<$ Index $>$}

$i$ : part type, $i=1,2, \ldots, N$, where $N$ is the number of products

$j:$ process plan

$k:$ tool

$l:$ pallet

$m$ : machine tool, $m=1,2, \ldots, M$, where $M$ is the number of machine tool type

$t$ : period, $t=1,2, \ldots, T$, where $T$ is the planning horizon

$<$ Set $>$

$S^{P P}(i)$ : Set of process plans related to part type $i$

$S^{i}(l)$ : Set of parts requiring pallet $l$

$S^{j}(i, l)$ : Set of process plans related to part type $i$ requiring pallet $l$

$S^{O}(j, k)$ : Set of operations for process plan $j$ requiring tool $k$

$S^{O}(j, l)$ : Set of operations for process plan $j$ requiring pallet $l$

$S^{O}(j, m)$ : Set of operations for process plan $j$ to be produced on machine tool $m$

\section{$<$ Decision variables $>$}

$x_{i j t}$ : Production quantity of part type $i$ produced following process plan $j$ in period $t$

$T X_{i t}$ : Production quantity of part type $i$ produced in period $t$ (aggregated over alternative process plans related to part $i)$

$I_{i t}$ : Inventory level of part type $i$ in period $t$

$B_{i t}$ : Backorder level of part type $i$ in period $t$

$T E_{i t}$ : Total energy consumed by part type $i$ produced in period $t$

\section{$<$ Parameters $>$}

$E_{i j}{ }^{\text {Total }}$ : total energy consumption $(k J)$ for machining a part type $i$ according to process plan $j$

$h_{i t}$ : inventory holding cost for a part type $i$ in period $t$

$\pi_{i t}$ : backorder cost for a part type $i$ in period $t$

$D_{i t}$ : demand for a part type $i$ in period $t$

$t_{p}$ : processing time (seconds) of operation $p$ (to be processed)

$t_{j}^{S}$ : time related to setup according to process plan $j$

$f_{i}$ : fluid amount (liter) consumed by following process plan $j$ of a part type $i$
$L_{k}^{\text {Tool }}$ : tool life of tool type $k$ (second)

$C^{\text {Fluid }}$ : Total usable liquid amount for each period in centralized liquid system (or the fluid amount for recycling)

$C_{k}^{\text {Tool }}$ : number of tool copies of tool type $k$

$C_{m}{ }^{\text {Machine }}$ : number of machine tool type $m$

$C_{l}^{\text {Pallet }}$ : number of pallet type $l$

$N_{l}{ }^{j}$ : maximum number of parts mounted on pallet type $l$ related to process plan $j$

$T$ : last period in planning horizon; planning duration over all periods

$W_{t}$ : available working time (seconds) of period $t$

Objective function

$\min \sum_{i}^{N} \sum_{t}^{T}\left(c_{1} \cdot T E_{i t}+c_{2} \cdot h_{i t} \cdot I_{i t}+c_{3} \cdot \pi_{i t} \cdot B_{i t}\right)$

Subject to

$$
\begin{aligned}
& T X_{i t}+I_{i t-1}-I_{i t}-B_{i t-1}+B_{i t} \geq D_{i t} \quad \forall i, \quad 1<t<T \\
& T X_{i t}-I_{i t}+B_{i t} \geq D_{i t} \quad \forall i, \quad t=1 \\
& T X_{i t}+I_{i t-1}-B_{i t-1} \geq D_{i t} \quad \forall i, \quad t=T \\
& \sum_{j \in S^{P P}(i)} x_{i j t}=T X_{i t} \quad \forall i, t \\
& \sum_{j \in S^{P P}(i)} E_{i j}^{\text {Total }} \cdot x_{i j t}=T E_{i t} \quad \forall i, t
\end{aligned}
$$

$\sum_{i=1}^{N} \sum_{j \in S^{P P}(i)} x_{i j t} \cdot\left(\sum_{p \in S^{O}(j, k)} t_{p}\right) \leq\left(C_{k}^{T o o l} \cdot L_{k}^{T o o l}\right) \forall k, t$

$\sum_{i=1}^{N} \sum_{j \in S^{P P}(i)} x_{i j t} \cdot\left(\sum_{p \in S^{O}(j, m)} t_{p}\right) \leq\left(C_{m}^{\text {Machine }} \cdot W_{t}\right) \forall m, t$

$\sum_{i \in S^{i}(l)} \sum_{j \in S^{j}(i, l)}\left(\frac{x_{i j t}}{N_{l}^{j}} \cdot\left(\sum_{p \in S^{O}(j, l)} t_{p}\right)+t_{j}^{S}\right) \leq\left(C_{l}^{\text {Pallet }} \cdot W_{t}\right) \quad \forall l, t$

$\sum_{i=1}^{N} \sum_{j \in S^{P P}(i)} x_{i j t} \cdot f_{i} \leq C^{\text {Fluid } \forall t}$

$T X_{i t}, T E_{i t}, I_{i t}, B_{i t} \geq 0 \quad \forall i, t$

$x_{i j t} \geq 0 \quad \forall i, j, t$

In (1), $c_{1}, c_{2}$, and $c_{3}$ denote the relative weights for energy consumption, inventory holding cost of parts, and backorder cost, respectively. Therefore, the objective function, which is to be minimized, denotes the weighted sum of energy consumption, inventory holding cost and backorder cost that are incurred in the system. 
Table 1 System configuration

\begin{tabular}{|c|c|}
\hline Resource Type & Considered System configuration \\
\hline Machine tool & $\begin{array}{l}5 \text { machine tools (MCM } 600 \text { 4-axes) } \\
1 \text { machine tools (MCM } 700 \text { 5-axes) }\end{array}$ \\
\hline Part handling system & $\begin{array}{l}\text { Two shuttles for } 4 \text {-axes machines } \\
\text { One robot for } 5 \text {-axes machine }\end{array}$ \\
\hline Pallet & $\begin{array}{l}\text { Square_Pallet with } 2 \text { setup faces (copies:5) } \\
\text { Cube_Pallet with } 4 \text { setup faces (copies:5) }\end{array}$ \\
\hline Tool & $\begin{array}{l}40 \text { tool types related to drill, boring bar, tap and } \\
\text { end mill processes are given. (each tool types } \\
\text { has } 15 \text { tool copies) }\end{array}$ \\
\hline Fluid transport system & Centralized fluid transport system \\
\hline Chip transport system & Centralized chip transport system \\
\hline Tool transfer system & - \\
\hline
\end{tabular}

Constraint (2-1) describes the relationship between the production, inventory, backorder and demand for different time periods (the inventory balance constraint) for each part type. It ensures that the sum of production, inventory level and backorder level is greater than or equal to customer demand for part type $i$ in each period. Constraint (2-2) is for the first period $(t=1)$ and constraint (2-3) is for the last period $(t=T)$.

Constraint (3) is a production equation for the total production amounts for part $i$ in period $t$. The total production amounts for part $i$ in period $t$ is equal to the aggregated production amounts over alternative process plans dedicated to part $i$ in period $t$. Constraint (4) is a energy consumption equation for production of part $i$ in period $t$. It represents the energy consumed by producing parts over alternative process plans dedicated to part $i$ in period $t$.

From constraint (5), (6), (7) and (8), the production planning model consider as the constraints for resources such as machine tools, tools, pallets, auxiliary system (cutting fluid system). The decision variables $x_{i j t}$ are used in all resource constraints.

Constraint (5) is a constraint for a tool resource. It ensures that the sum of processing times for all operations dedicated to a specific tool type $k$ should be less than the total available time of the tool type in period $t$. The total available time of a

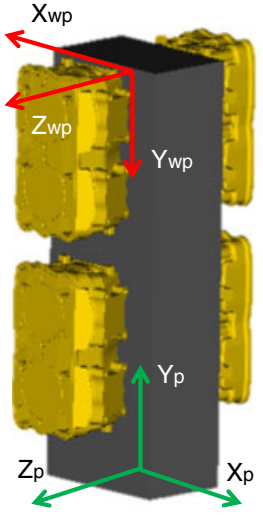

(a) Square type

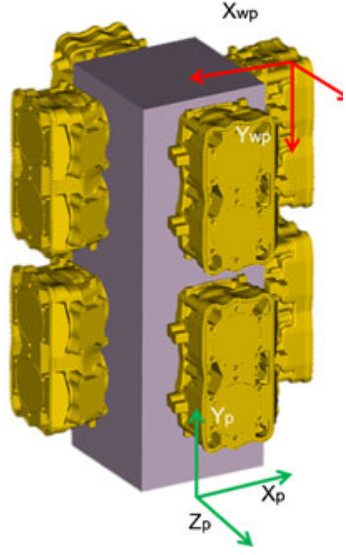

(b) Cube type
Fig. 3 Example of pallet configuration for Part type '492'

tool type $k$ in period $t$ can be calculated by using a simple production between the deterministic tool life of a specific tool type and the number of copies of the tool type in period $t$.

Constraint (6) is a constraint for a machine tool resource. It ensures that the cumulative processing times of all operations dedicated to the specific machine tool $m$ cannot exceed the total available machining time capacity of the machine tool in period $t$. The total available machining time capacity of the machine tool is calculated by using a simple production between number of the machine tool and the time unit of period $t$.

Constraint (7) is a constraint for a pallet resource. Each pallet type has different number of parts which can be mounted on the pallet. The constraint ensures that the sum of required processing times in order to machine parts mounted on pallet type $l$ and setup times to mount the parts on the pallet type $l$ should be less than the total available times for the pallet type $l$. The total available time for the pallet type is calculated by using the product between the number of the pallet type $l$ and the time unit of period $t$.

Constraint (8) is a cutting fluid capacity constraint. The constraint ensures that the cumulative fluid usage requirement to manufacture production amounts cannot exceed the

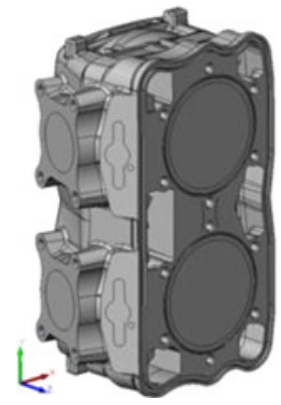

Part '492'

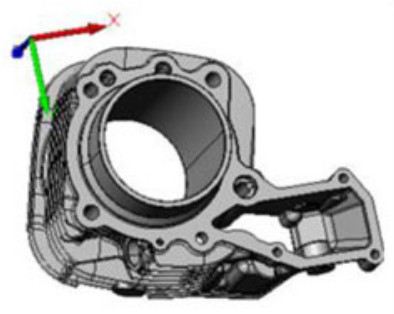

Part '311'

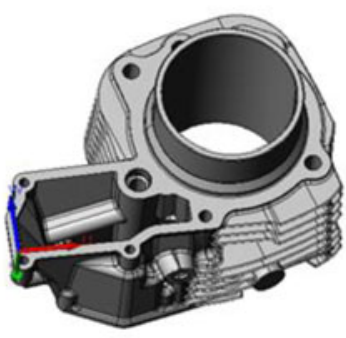

Part ' 312 '

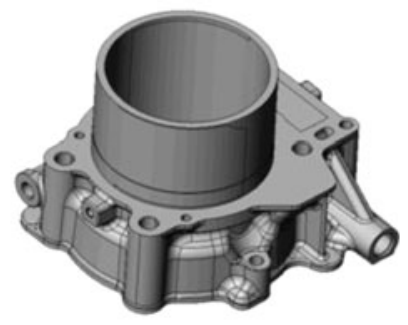

Part '377'

Fig. 2 Family of parts considered 


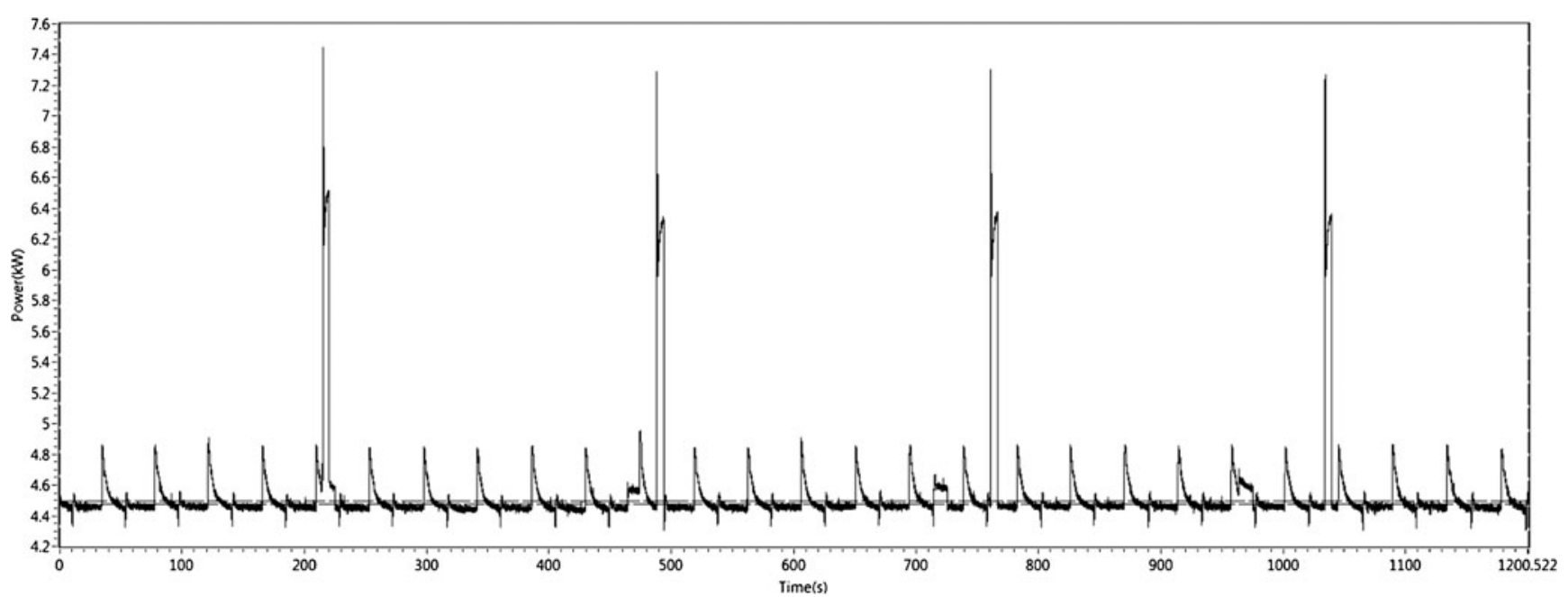

Fig. 4 Power profile for the idle state of the MCM Clock 700 machine

capacity limit of the tank size (or fluid amount for recycling during the period $t$ ) of the centralized fluid system. Constraint (9) and (10) are non-negative constraints for all decision variables.

\section{Industrial use case study}

This section presents an industrial case study for machining on a FMS composed by 5 MCM Clock 600CIM horizontal machines (4-axes) and one MCM Clock 700CIM horizontal machine (5-axes) with material handling systems (such as shuttle and robot), centralized fluid transport system and chip transport systems as can be seen in Table 1. After installing the initial system, one MCM Clock 700 is added on the FMS and a robot system is installed as material handling system dedicated to the machine. The information (type and copies) for available pallet and tool are given.

The considered family of products is composed by four part types belonging to the engine cylinder family. The part ' 492 ' is produced for recreational market (snowmobiles, outboards engines, all-terrain vehicles) and the part ' 311 ', ' 312 ' and ' 377 ' are produced for the 2 -wheel market as can be seen in Fig. 2. Products have small and medium dimensions and are characterized by drilling and milling operations.

A process plan related to the part ' 492 ' has the following data to specify technological instructions describing how to make the part: a set of operations/precedence between operations/processing time, feed rate, spindle speed, cutting depth, tool, material removal rate, etc. for each operation/ machine tools and pallets. The part is presented as an example analyzed by Copani et al. [8] and Pellegrinelli et al. [20]. It presents 23 features, 63 operations, 63 Machining Working Step (MWS)s, 2 holding surfaces and 40 precedence constraints. The considered MWSs present besides different tool access directions and also different tool cutting parameters.

Two alternative pallets were taken into account for the machining of the part '492': (a) a square $430 \mathrm{~mm} \times 590 \mathrm{~mm} \times$ $100 \mathrm{~mm}$ and (b) a cube $400 \mathrm{~mm} \times 590 \mathrm{~mm} \times 400 \mathrm{~mm}$. For a square type, the pallet is characterized by two faces as can be seen in Fig. 3. Two workpieces are mounted on each face (1 column, 2 rows). A back draft angle of $15^{\circ}$ is considered. The pallet can be processed by the 4-axis MCM Clock 600 CIM. The pallet (b) presents the biggest fixture in accordance to the machine tool working cube. The pallet is characterized by four faces.

Multiple process plans for a part type is defined on the basis of alternative operations and alternative machine tools. In addition, alternative setup planning and alternative pallet configuration should be considered to define additional process plans. The setup planning problem consists in determining the number of orientations (setups). Each change in the orientation of the workpiece requires an un-mounting and re-mounting of the workpieces on the fixture, which involves a certain time utilization and may compromise the machining precision and manufacturing quality. The pallet configuration means to decide the number, disposition (pattern) and the mix of pieces to

Table 2 Steady-state powers for spindle in two different machine tools

\begin{tabular}{llll}
\hline \multicolumn{2}{l}{ MCM Clock 600} & \multicolumn{2}{l}{ MCM Clock 700} \\
\hline $\begin{array}{c}\text { Speed Level } \\
\text { (RPM) }\end{array}$ & $\begin{array}{c}\text { Average Steady-state } \\
\text { power (kW) }\end{array}$ & $\begin{array}{c}\text { Speed Level } \\
\text { (RPM) }\end{array}$ & $\begin{array}{c}\text { Average Steady-state } \\
\text { power (kW) }\end{array}$ \\
2000 & 0.7 & 3000 & 0.16 \\
4000 & 2.15 & 6000 & 0.28 \\
6000 & 3.34 & 9000 & 0.36 \\
8000 & 3.18 & 12000 & 0.61 \\
10000 & 2.97 & 15000 & 0.98 \\
\hline
\end{tabular}




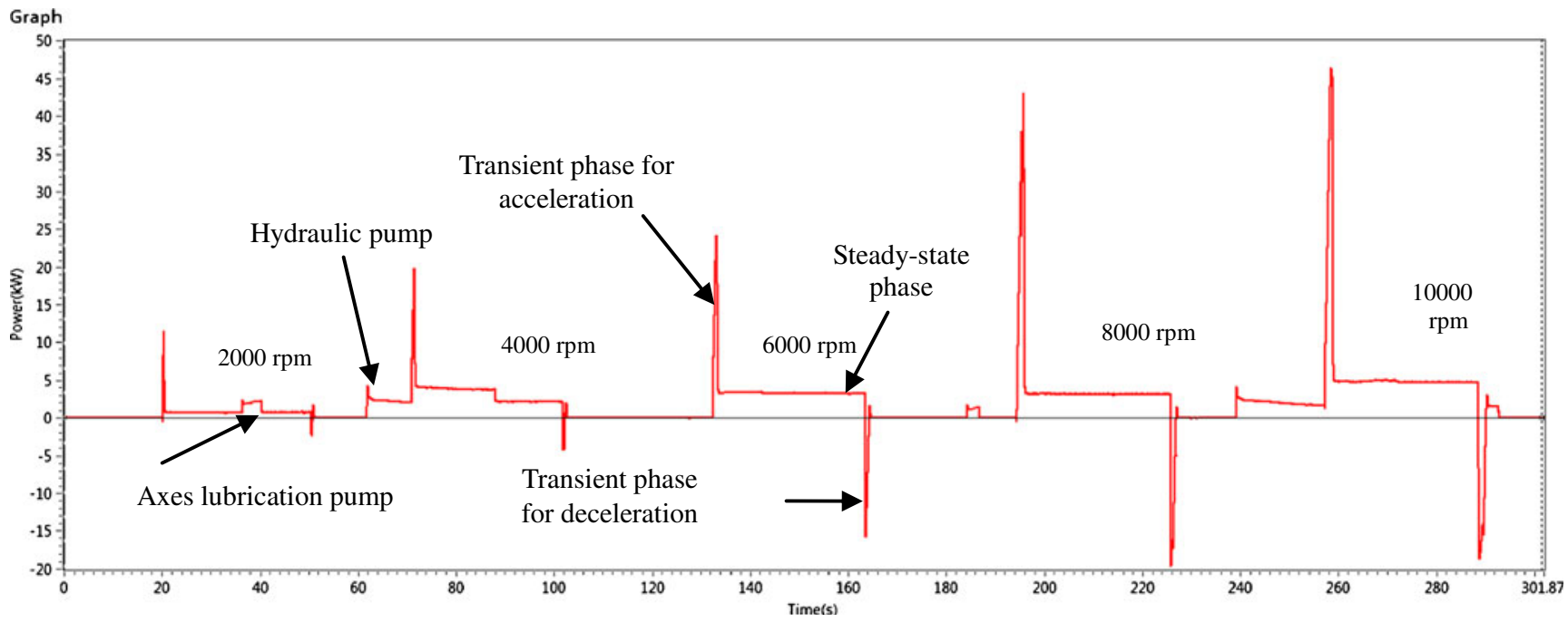

Fig. 5 MCM Clock 600 machine spindle power profile during steady-state and transient phases

be clamped on the fixturing device of the pallet as well as part positions and operations [20].

The power measurement for all power driven resources are processed as the same procedure measured by Avram and Xirouchakis [3]. The idle power due to continuous running of the machine components can be averaged at $4.46 \mathrm{~kW}$ and $2.16 \mathrm{~kW}$ for MCM Clock 700 and MCM Clock 600, respectively. Apart from the numerical control and the electronics of the machine, the spindle gear preload hydraulic pump and the spindle chiller recirculation pump run continuously while the machine is idle. However, due to the intermittent functioning of three other components such as pump of the hydraulic, refrigeration unit of the spindle and axes lubrication pump, the idle power shifts to $4.52 \mathrm{~kW}$ and $3.13 \mathrm{~kW}$ for MCM Clock 700 and Clock 600, respectively. For example, the power profile for the idle state of the Clock 700 machine is depicted in Fig. 4.
For a steady-state power of spindle and axes at a specific speed and feed rate, we can assume it through a simple linear interpolation if power data at various speeds are available for the spindle and the axes. The power amplitudes at 4 different speeds for the 5 axes on the MCM Clock 700 and for the 4 axes of the MCM Clock 600 were measured respectively. In addition, the power profiles for the spindle state were recorded on both machine tools during the successive running of the spindle at five speed levels without braking (no spindle brake between consecutive speeds).

Three tests were performed while running MCM Clock 700 's spindle at 5 speed levels (3000-6000-9000-12000 $15000, \mathrm{rpm})$ as can be seen Table 2. We have observed similar power amplitudes for all the accelerations but in terms of energy, the higher the speed the higher the consumption mainly due to the lengthening of the acceleration time. Three tests were also performed while running MCM Clock 600's spindle at 5

Table 3 Power measurement data in Industry use case

\begin{tabular}{|c|c|c|c|}
\hline \multirow[t]{2}{*}{ INDEX } & \multirow[t]{2}{*}{ DEFINITION } & \multicolumn{2}{|l|}{ Power Measurement data } \\
\hline & & MCM 600 (4-axes) & MCM 700 (5-axes) \\
\hline$P_{\text {idle }}$ & the idle power of the machine $(\mathrm{kW})$ & 3.13 & 4.52 \\
\hline$P_{p c}$ & the average power required to exchange pallets $(\mathrm{kW})$ & 0.47 & - \\
\hline$P_{\text {stead-state }}$ & $\begin{array}{l}\text { the average power to run the spindle and feed axes at the } \\
\text { process programmed speeds }(\mathrm{kW})\end{array}$ & Linear interpolation & Linear interpolation \\
\hline$P_{t c}$ & the average power required to change the tool $(\mathrm{kW})$ & 0.81 & 0.59 \\
\hline$P_{\text {screw }}$ & the delivery screw power to remove chip (kW) & 0.37 & 0.37 \\
\hline$P_{\text {pump }}$ delivery & the cutting fluid delivery power $(\mathrm{kW})$ & $\begin{array}{l}\text { 9.8/low pressure power } \\
12 / \text { high pressure power }\end{array}$ & 9.8/low pressure power \\
\hline$P_{\text {pump }}{ }^{\text {return }}$ & the cutting fluid return power $(\mathrm{kW})$ & 2.4 & 1.29 \\
\hline$P_{m i s c}$ & $\begin{array}{l}\text { the average power level corresponding to other machine tool } \\
\text { components that run during machining or while idling }(\mathrm{kW})\end{array}$ & - & - \\
\hline$P_{c u t}$ & $\begin{array}{l}\text { the power required to remove a specific amount of material } \\
\text { through the process } p(\mathrm{~kW})\end{array}$ & Formula & Formula \\
\hline
\end{tabular}


Table 4 Power measurement data for material handling system

\begin{tabular}{llllll}
\hline Its Type & $\begin{array}{l}\text { Operation } \\
\text { Mode }\end{array}$ & $\begin{array}{l}\text { Material } \\
\text { Conveyed }\end{array}$ & $\begin{array}{l}\text { Speed } \\
(\mathrm{m} / \mathrm{s})\end{array}$ & $\begin{array}{l}\text { Driving } \\
\text { Power } \\
(\mathrm{kW})\end{array}$ & $\begin{array}{l}\text { Load/Unload } \\
\text { Time (second) }\end{array}$ \\
\hline $\begin{array}{c}\text { Chain } \\
\text { conveyor }\end{array}$ & Continuous & Chips & 0.2 & 1.2 & - \\
$\begin{array}{l}\text { Screw } \\
\text { conveyor }\end{array}$ & Intermittent & Chips & 0.1 & 0.37 & - \\
$\begin{array}{l}\text { Robot } \\
\text { Shuttle }\end{array}$ & Intermittent & Parts & 1 & 0.62 & 19.91 \\
\hline
\end{tabular}

speed levels (2000-4000-6000-8000-10000, rpm). The MCM Clock 600 spindle power profiles during steady-state with respect to the aforementioned five speed levels are depicted in Fig. 5 and the power requirements are also summarized in Table 2. On the contrary, the cutting power is estimated through formula as mentioned in Section 2.

The FMS is equipped with a centralized cooling/lubrication system consisting of 3 low pressure pumps, 3 high pressure pumps and other components responsible for the filtration of the cutting fluid. The cutting fluid employed is a watercommercial emulsion which is stored in the centralized coolant tank having a limited capacity. If at least one machine is requesting cutting fluid, all the three low pressure pumps are simultaneously activated. The cutting fluid delivery powers were recorded.

The powers for tool change and pallet change activity were also recorded. The driving power for chip removal system was recorded to evacuate chips outside the machine tool area and a lifting conveyor. The miscellaneous power and return power weren't measured in this case. Since the tool movement system is not installed on the considered FMS, the energy consumed with respect to the tool handling activities doesn't be considered. The power measurements for all power driven resources related to MCM Clock 600 and MCM Clock 700 are summarized in Table 3.

There are two different material (part) handling systems for a part movement, robot and shuttle. For a robot, this is a 6-axes robot fixed on the floor. It performs the part loading/unloading activities between the operator station, storage area and only one machine tool with 5 -axes. The power profile was recorded while the robot executed various movements between the machine and storage area (upward, downward, advance, retract, grab/release the part). For instance, a typical unloading/ loading mission (unload finished part from the machine pallet and transfer to storage area, grab raw part from storage area and load onto the machine pallet) draws in average $0.62 \mathrm{~kW}$.

Basically, the startup of the shuttle system consists in the mere powering of the controller unit followed by the activation of the servo drives of the two shuttles responsible for pallets loading/unloading between the operator stations, storage area and 5 machine tools with 4-axes. The average power will increase to $0.86 \mathrm{~kW}$ after the powering routine of the two shuttles is completed. Table 4 shows power measurement data for material handling systems (conveyor, robot and shuttle) in the considered FMS.

Table 5 Energy consumption with respect to alternative process plans of part 492

\begin{tabular}{|c|c|c|c|c|c|c|c|}
\hline \multicolumn{2}{|l|}{ ProcessPlanID } & \multicolumn{2}{|l|}{ 492-PP-1 } & \multicolumn{2}{|l|}{ 492-PP-2 } & \multicolumn{2}{|l|}{ 492-PP-3 } \\
\hline \multicolumn{2}{|c|}{ Machine tool type/Pallet type } & \multicolumn{2}{|c|}{$\begin{array}{l}\text { MCM } 600 \text { (Four Axes } \\
\text { Horizontal Spindle) } \\
\text { Square Type Pallet }\end{array}$} & \multicolumn{2}{|c|}{$\begin{array}{l}\text { MCM } 600 \text { (Four Axes } \\
\text { Horizontal Spindle) } \\
\text { Cube Type Pallet }\end{array}$} & \multicolumn{2}{|c|}{$\begin{array}{l}\text { MCM } 700 \text { (Five Axes } \\
\text { Horizontal Spindle) } \\
\text { Square Type Pallet }\end{array}$} \\
\hline & & Total energy & $\begin{array}{l}\text { energy consumption } \\
\text { (ratio) }\end{array}$ & Total energy & $\begin{array}{l}\text { energy consumption } \\
\quad \text { (ratio) }\end{array}$ & Total energy & $\begin{array}{l}\text { energy consumption } \\
\text { (ratio) }\end{array}$ \\
\hline \multirow{9}{*}{$\begin{array}{l}\text { Part machining } \\
\text { energy (Ratio) }\end{array}$} & idle & \multirow[t]{9}{*}{$2435.9 k J(99.5 \%)$} & $884.0 \mathrm{~kJ}(36.1 \%)$ & \multirow{9}{*}{$\begin{array}{l}2406.2 \mathrm{~kJ} \\
(99.5 \%)\end{array}$} & $873.4 k J(36.1 \%)$ & \multirow{9}{*}{$\begin{array}{l}3599.1 \mathrm{~kJ} \\
\quad(99.7 \%)\end{array}$} & $1266.4 k J(35.1 \%)$ \\
\hline & Delivery Pump & & $54.7 \mathrm{~kJ}(2.2 \%)$ & & $54.0 \mathrm{~kJ}(2.2 \%)$ & & $20.8 k J(0.6 \%)$ \\
\hline & Cutting & & $977.0 \mathrm{~kJ}(40.0 \%)$ & & $940.7 k J(38.9 \%)$ & & $953.0 \mathrm{~kJ}(26.4 \%)$ \\
\hline & Chip & & $104.5 \mathrm{~kJ}(4.3 \%)$ & & $103.3 \mathrm{~kJ}(4.3 \%)$ & & $103.7 \mathrm{~kJ}(2.9 \%)$ \\
\hline & Stead state & & $94.7 \mathrm{~kJ}(3.9 \%)$ & & $93.7 \mathrm{~kJ}(3.9 \%)$ & & $849.2 \mathrm{~kJ}(23.5 \%)$ \\
\hline & Return Pump & & $24.8 \mathrm{~kJ}(1.0 \%)$ & & $24.5 \mathrm{~kJ}(1.0 \%)$ & & $25.8 k J(0.7 \%)$ \\
\hline & Miscellaneous & & $0.0 \mathrm{~kJ}(0.0 \%)$ & & $0.0 \mathrm{~kJ}(0.0 \%)$ & & $0.0 \mathrm{~kJ}(0.0 \%)$ \\
\hline & Tool change & & $275.8 k J(11.3 \%)$ & & $275.8 \mathrm{~kJ}(11.4 \%)$ & & $357.7 \mathrm{~kJ}(9.9 \%)$ \\
\hline & Pallet change & & $20.4 k J(0.8 \%)$ & & $40.8 \mathrm{~kJ}(1.7 \%)$ & & $22.6 \mathrm{~kJ}(0.6 \%)$ \\
\hline \multirow{2}{*}{$\begin{array}{l}\text { Part handling } \\
\text { energy }\end{array}$} & Shuttle & \multirow[t]{2}{*}{$1.95 k J(0.1 \%)$} & $1.6 \mathrm{~kJ}(0.1 \%)$ & \multirow{2}{*}{$\begin{array}{l}1.95 \mathrm{~kJ} \\
\quad(0.1 \%)\end{array}$} & $1.6 k J(0.1 \%)$ & \multirow{2}{*}{$\begin{array}{l}12.3 \mathrm{~kJ} \\
\quad(0.3 \%)\end{array}$} & $0.00 \mathrm{~kJ}(0.0 \%)$ \\
\hline & Robot & & $0.00 \mathrm{~kJ}(0 \%)$ & & $0.00 \mathrm{~kJ}(0 \%)$ & & $12.3 \mathrm{~kJ}(0.3 \%)$ \\
\hline \multicolumn{2}{|l|}{$\begin{array}{l}\text { Chip transport } \\
\text { energy }\end{array}$} & \multicolumn{2}{|l|}{$9.2 \mathrm{~kJ}(0.4 \%)$} & \multicolumn{2}{|c|}{$9.2 \mathrm{~kJ}(0.4 \%)$} & \multicolumn{2}{|l|}{$0.00 \mathrm{~kJ}(0 \%)$} \\
\hline \multicolumn{2}{|l|}{$\begin{array}{l}\text { Total energy } \\
\text { consumption }\end{array}$} & \multicolumn{2}{|l|}{$2447.4 k J(100 \%)$} & \multicolumn{2}{|c|}{$2417.4 k J(100 \%)$} & \multicolumn{2}{|c|}{$3611.5 k J(100 \%)$} \\
\hline
\end{tabular}


Table 6 Energy and material flows for alternative process plans related to each part type

\begin{tabular}{|c|c|c|c|c|c|c|c|}
\hline Part & Process Plan & Number of operations & Machine tool & Pallet & Energy consumption & Chip cutting volume & Consumed Fluid \\
\hline \multirow[t]{3}{*}{492} & 492-PP-1 & 63 & MCM 600 & Square & $2447.4 \mathrm{~kJ}$ & $1043.3 \mathrm{~cm}^{3}$ & $6.25 \mathrm{~L}$ \\
\hline & 492-PP-2 & 63 & MCM 600 & Cube & $2417.4 \mathrm{~kJ}$ & $1043.3 \mathrm{~cm}^{3}$ & $6.25 \mathrm{~L}$ \\
\hline & 492-PP-3 & 63 & MCM 700 & Square & $3611.5 \mathrm{~kJ}$ & $1043.3 \mathrm{~cm}^{3}$ & $6.25 \mathrm{~L}$ \\
\hline 311 & 311-PP-1 & 23 & MCM 600 & Square & $1547.6 \mathrm{~kJ}$ & $72.9 \mathrm{~cm}^{3}$ & $0.44 \mathrm{~L}$ \\
\hline \multirow[t]{2}{*}{312} & 312-PP-1 & 24 & MCM 600 & Square & $1588.4 \mathrm{~kJ}$ & $126.05 \mathrm{~cm}^{3}$ & $0.76 \mathrm{~L}$ \\
\hline & 312-PP-2 & 24 & MCM 600 & Cube & $1567.0 \mathrm{~kJ}$ & $126.05 \mathrm{~cm}^{3}$ & $0.76 \mathrm{~L}$ \\
\hline \multirow[t]{2}{*}{377} & 377-PP-1 & 41 & MCM 600 & Square & $1829.4 \mathrm{~kJ}$ & $249.4 \mathrm{~cm}^{3}$ & $1.5 \mathrm{~L}$ \\
\hline & 377-PP-2 & 41 & MCM 600 & Cube & $1822.6 \mathrm{~kJ}$ & $249.4 \mathrm{~cm}^{3}$ & $1.5 \mathrm{~L}$ \\
\hline
\end{tabular}

Table 5 shows the energy consumption for 3 alternative process plans (492-PP-1, 492-PP-2 and 492-PP-3) for the part ' 492 ' on a basis of alternative pallets (square and cube) and alternative machine tools (4-axes and 5-axes). The estimation of the energy consumption can be approached in terms of consumption intensity based on various machine tool states. We also see that the part machining energy consumption is higher than others such as part handling energy and chip transport energy. The part machining energy for the part '492' with square pallet and cube pallet is $2435.9 \mathrm{~kJ}$ and $2406.2 \mathrm{~kJ}$, respectively. The energy difference between both is due to different pallet change energy and process time.

From the production planning perspective, it is difficult to estimate exact loading/unloading location and times between all machine tools and a storage area. Only we can estimate the material handing energy for the shuttle system on the basis of only some sample data. In this test, the difference of an energy consumption by the process plan '492-PP-3' is due to energy for different material handling, chip transport and idle/statestate power on MCM Clock 700 without a centralized cutting chip transfer system. Parts loaded on MCM Clock 700 are handled by a robot system instead of a shuttle system. Table 6 shows the estimated energy consumption and material flows such as cutting chip generated and the fluid consumed in terms of alternative process plans for considered 4 different parts.

Figure 6 shows a result for the production planning in order to satisfy the customer demands on the basis of given system configuration. We can see that a set of process plans (311-PP1, 312-PP-2 and 377-PP-2) with minimum energy consumption is selected among alternative process plans for each part to satisfy the demands over the planning horizon (3 months). For the part '492', the process plan '492-PP-2' with minimum energy consumption is selected. Although the process plan '492-PP-1' is alternative process plan with next minimum energy consumption, the process plan '492-PP-3' (machined on MCM Clock 700) with maximum energy consumption is also selected since the lack of capacity for MCM Clock 600 machine in some periods.

In this paper, the objective function addressing the minimization of the weighted sum of the energy consumption, inventory holding cost and backorder cost can be formulated in an attempt to find the optimal solution. The relative weight values $\left(c_{1}, c_{2}\right.$, and $\left.c_{3}\right)$ for energy consumption, inventory holding cost of parts, and backorder cost in the objective

Fig. 6 Production planning

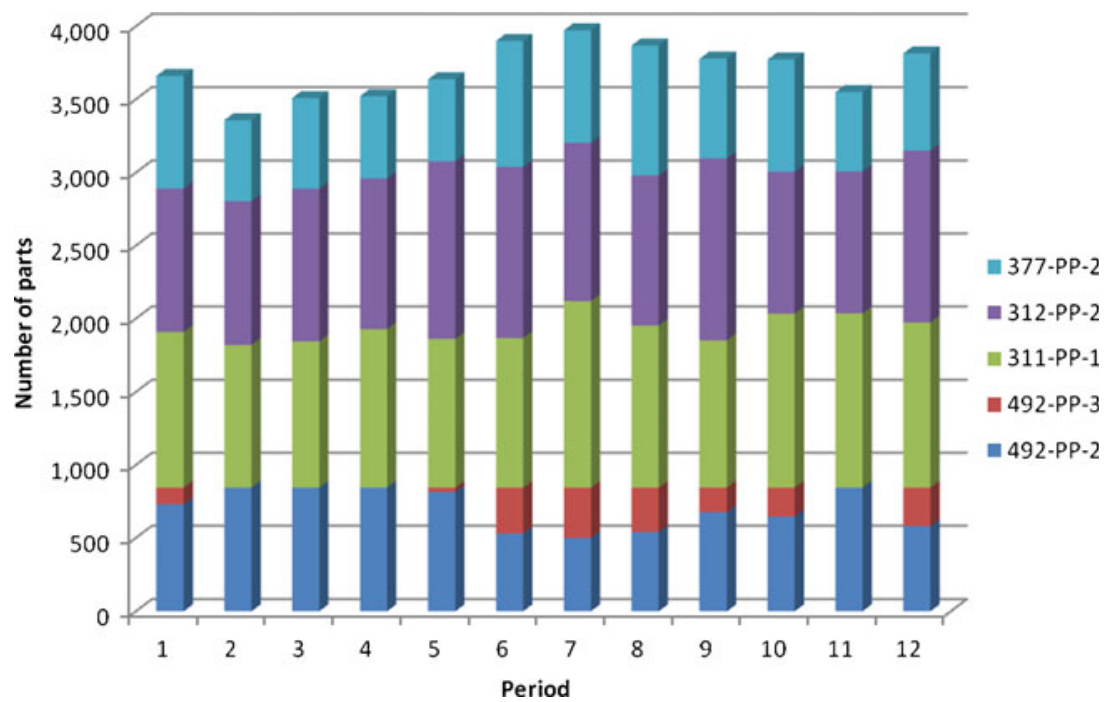


Fig. 7 Energy consumption

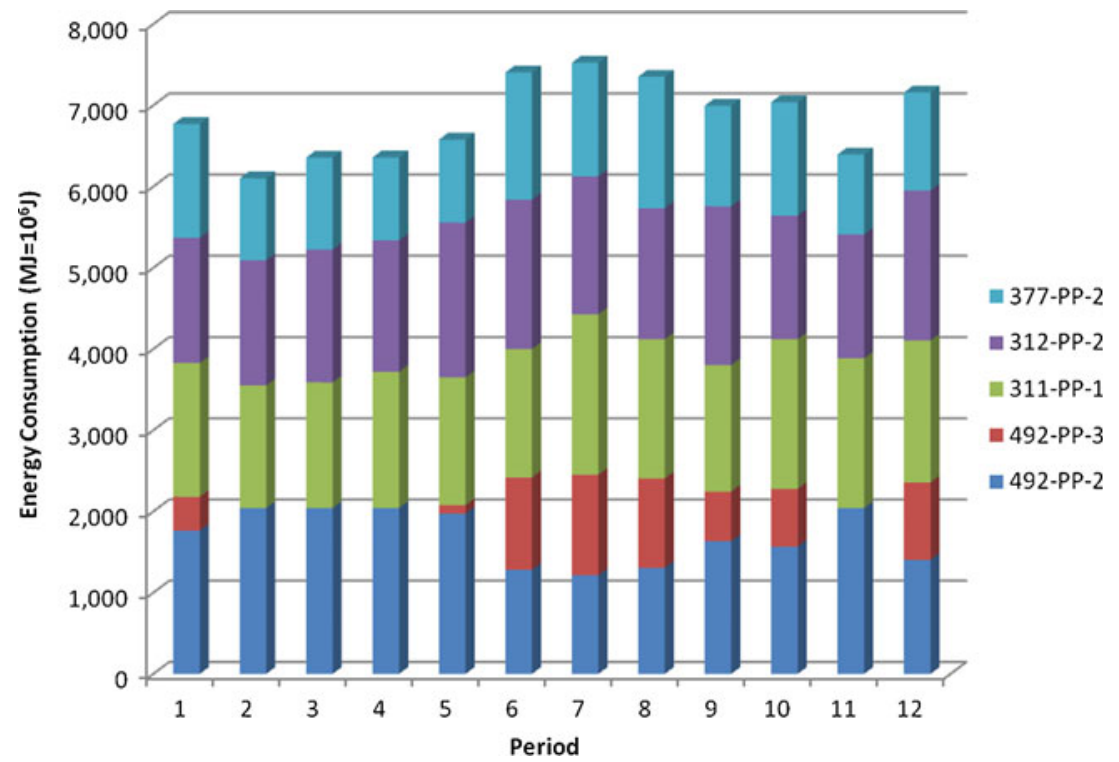

function represent $0.01,500$ and 500, respectively. Figure 7 represents the energy consumed with respect to selected process plans for each part type to satisfy the customer demands from the results of the production planning. In addition, Fig. 8 represents the profiles for the cutting fluid volume consumed and the cutting chips volume incurred on the considered system during the planning horizon.

From the above results, we can argue that from the proposed energy/materials flows estimation model and production planning model, one can obtain the assessment of the energy consumption in terms of multiple process plans that are incurred at a system level as well as the evaluation of the environmental performance (total energy consumption, chip fluids consumed and chips volume generated) for a production planning. In addition, the industrial use case results emphasize the need for production planning model accounting for minimum energy consumption.

The additional tests are done in terms of different weighted values $\left(c_{1}, c_{2}\right.$, and $\left.c_{3}\right)$ for energy consumption, inventory holding cost and backorder cost in the objective function. Figure 9 represents total energy consumption difference according to different weighted values for energy consumption and inventory cost. We assume that the value of $c_{3}$ is the same as that of $c_{2}$. In a case of a relatively small difference of the weighted values between energy consumption and inventory cost (e.g. $c_{1}=1$ and $c_{2}=50$ ), we can obtain lower total energy consumption due to the production by process plans with lower energy consumption through the inventory strategy if
Fig. 8 Fluid volume consumed and Chip volume generated

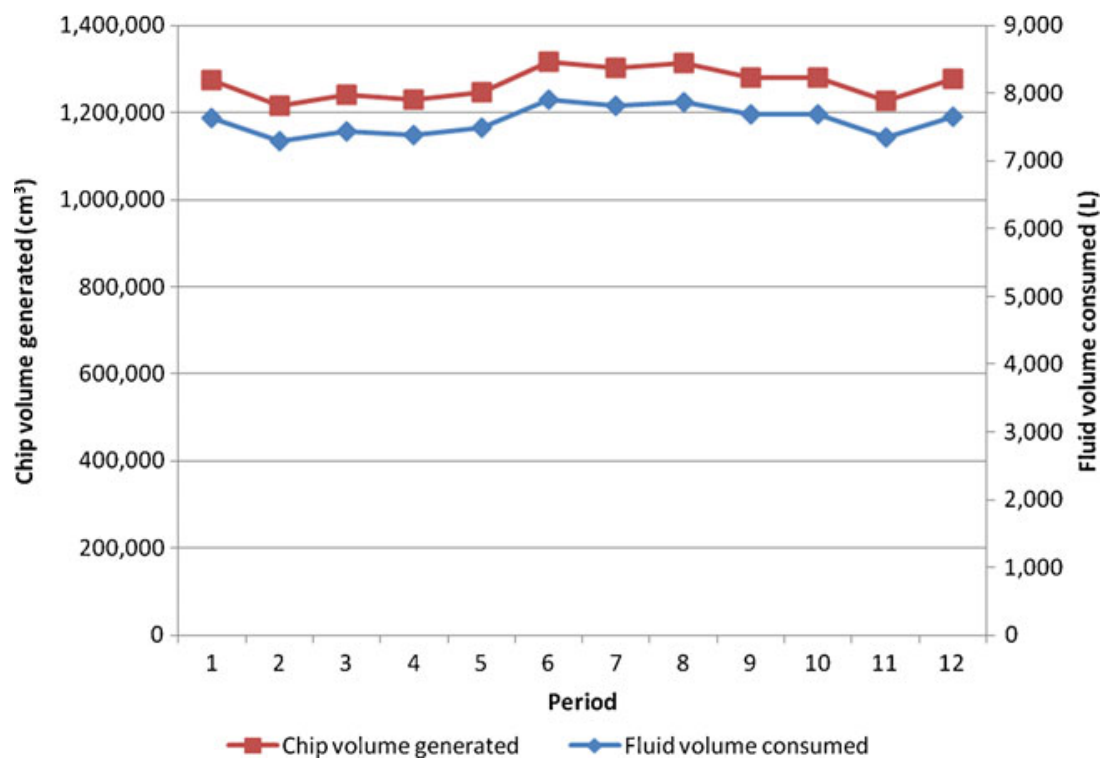


Fig. 9 Total energy consumption in terms of different weighted values for energy consumption and inventory costs

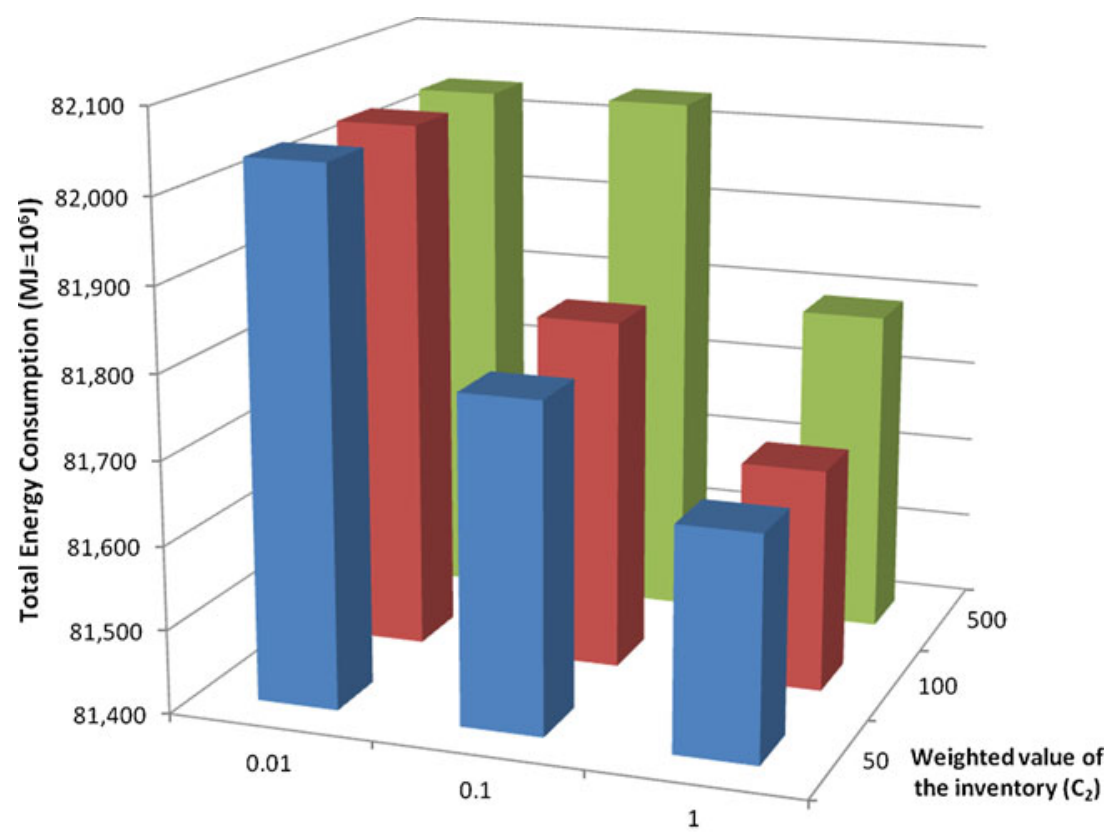

Weighted Value of the energy consumption $\left(C_{1}\right)$ there is the remaining capacity in prior periods instead of producing parts according to a process plan with higher energy consumption to satisfy the demands in a period.

The traditional production costs consist of fixed costs and variable costs incurred in producing goods. Especially, the variable costs are costs that vary directly with output since more variable units are required to increase output. Examples are the costs of essential raw materials and components, the wages of part-time staff or employees paid by the hour, the costs of electricity and gas and depreciation of capital inputs due to wear and tear. Total variable cost rises as output increases. In traditional manufacturing, energy is necessary for machines to work; thus, energy consumption follows production. The energy can be considered by variable cost category (less than proportionally). The energy is easily converted to electricity costs.

All formulations tested in this study were coded in $\mathrm{C}++$ and computational tests have been carried out on a personal computer with a Core ${ }^{\mathrm{TM}} \mathrm{i} 7$ processor operating at $2.93 \mathrm{GHz}$ clock speed. Also, a pre-processing for energy and material flows and LP formulation has been implemented in $\mathrm{C}++$ using CPLEX 12.1 to solve the production planning problems. The all data were handled on MS Access DB.

\section{Conclusions}

In this paper, we presented a production planning problem in highly automated manufacturing system considering multiple process plans with different energy requirements. We consider a linear programming model with the objective to minimize the weighted sum of energy consumption, inventory holding cost and backorder cost, subject to linear constraints pertaining to various resources (machine tool, tool, pallet and auxiliary system with centralized cutting fluid system). The total energy consumption is a sum of the following components, namely energy for a part machining, material (part) handling, tool transport and a chip transport. For a given customer's demand and manufacturing system configuration, we presented a new methodology for an estimation of energy consumption and material flows incurred at a system level with respect to multiple production plans for a part type. The proposed production planning model is tested under an industrial use case study.

Considering the result for the production planning such as total energy consumed, we can argue that the developed model gives a production planning with the minimum energy consumption to satisfy the customer demands. In addition, environmental effects such as the cutting fluid consumed and the volume of chips removed can be estimated. Future extension of this work will consider the approach with reference to two directions. A first extension would consider a capacity planning for diverse production system configurations characterized by frequent changes of the part families demand while the second extension would deal with an integration model between the production planning and scheduling with the objective of minimizing the energy consumption.

Acknowledgments The partial financial support from the EU Seventh Framework Programme Theme 4 project DEMAT (De-materialized Manufacturing system: A new way to design, build, use and sell European Machine Tools) under Grant No. 2010-246020-2 is also gratefully acknowledged. 


\section{References}

1. Albey E, Bilge U (2011) A hierarchical approach to FMS planning and control with simulation-based capacity anticipation. Int J Prod Res 49:3319-3342

2. Avram OI, Stroud I, Xirouchakis P (2011) A multi-criteria decision method for sustainability assessment of the use phase of machine tool systems. Int J Adv Manuf Technol 53:811-828

3. Avram OI, Xirouchakis P (2011) Evaluating the use phase energy requirements of a machine tool system. J Clean Prod 19:699-711

4. Bang JY, Kim Y-D (2010) Hierarchical production planning for semiconductor wafer fabrication based on linear programming and discrete-event simulation. IEEE Trans Autom Sci Eng 7:326-336

5. Bettoni L, Zanoni S (2012) Energy implications of production planning decisions. Adv Prod Manag Syst. Value Netw: Innov Technol Manag 384:9-17

6. Byrne MD, Hossain MM (2005) Production planning: an improved hybrid approach. Int J Prod Econ 93-94:225-229

7. Cannata A, Karnouskos S, Taisch M (2010) Energy efficiency driven process analysis and optimization in discrete manufacturing. Industrial Electronics, IECON'09-35th Annual Conference of IEEE

8. Copani G, Leonesio M, Molinari Tosatti L, Pellegrinelli S, Urgo M, Valente A, Zulaika J (2012) Holistic approach for jointly designing dematerialized machine tools and production systems enabling flexibility-oriented business models. Leveraging Tech Sustain World. doi:10.1007/978-3-642-29069-5_36, 209-214

9. Dahmus JB, Gutowski TG (2004) An environmental analysis of machining. In: Proceedings of IMECE 2004, November 13e19, Anaheim, California, USA

10. Doh H-H, Yu J-M, Kim J-S, Lee D-H, Nam S-H (2013) A priority scheduling approach for flexible job shops with multiple process plans. Int J Prod Res 51:3748-3764

11. Jiang ZG, Zhang H, Sutherland JW (2012) Development of an environmental performance assessment method for manufacturing process plans. Int J Adv Manuf Technol 58:783-790

12. Kara S, Manmek S, Herrmann C (2010) Global manufacturing and the embodied energy of Products. Ann CIRP 59:29-32

13. Kim B, Kim S (2001) Extended model for a hybrid production planning approach. Int J Prod Econ 73:165-173

14. Kim Y-D, Lee G-C, Choi S-K, Lim S-K (2001) Tool requirements planning in a flexible manufacturing system with an automatic tool transporter. IEEE Trans Robot Autom 17:795-804

15. Marx DJL (2005) Energy audit methodology for belt conveyors. Master thesis
16. Mitra S, Grossmann IE, Pinto JM, Arora N (2012) Optimal production planning under time-sensitive electricity prices for continuous power-intensive processes. Comput Chem Eng 38:171-184

17. Mouson G, Yildirim MB (2008) A framework to minimise total energy consumption and total tardiness on a single machine. Int $\mathrm{J}$ Sustain Eng 1:105-116

18. Mouson G, Yildirim MB, Twomey J (2007) Operational methods for minimization of energy consumption of manufacturing equipment. Int J Prod Res 45:4247-4271

19. Ozguven C, Ozbakir L, Yavuz Y (2010) Mathematical models for job-shop scheduling problems with routing and process plan flexibility. Appl Math Model 34(6):1539-1548

20. Pellegrinelli S, Valente A and Molinari Tosatti L (2012) An integrated setup planning and pallet configuration approach for highly automated production system with energy modelling of manufacturing operations. 45th CIRP Conference on Manufacturing System. pp 49-54

21. Rajabinasab A, Mansour S (2011) Dynamic flexible job shop scheduling with alternative process plans: an agent-based approach. Int J Adv Manuf Technol 54:1091-1107. doi:10.1007/s00170-0102986-7

22. Saad G (1982) An overview of production planning model: structure classification and empirical assessment. Int J Prod Res 20:105-114

23. Seow Y, Rahimifard (2011) A framework for modeling energy consumption within manufacturing systems. CIRP J Manuf Sci Technol $4: 258-264$

24. Soavi F, Zurla O (1997) Performance evaluation of a new screw conveyor for metal swarf. Int J Mach Tools Manuf 37:981-996

25. Weinert N, Chiotellis S, Seliger G (2011) Methodology for planning and operating energy-efficient production systems. CIRP Ann Manuf Technol 60:41-44

26. Weinert N, Rohrmus D, Dudeck S (2012) Energy-aware production planning based on energyblocks in a siemens $\mathrm{AG}$ generator plant. Sustain Manuf 211-216

27. Yildirim MB, Mouson G (2012) Single-machine sustainable production planning to minimize total energy consumption and total completion time using a multiple objective genetic algorithm. IEEE Trans Eng Manuf 59:585-597

28. Zhang L, Li X, Gao L, Zhang G, Wen X (2012) Dynamic scheduling model in FMS by considering energy consumption and schedule efficiency. Preceeding of the 2012 I.E. 16th International Conference Supported Cooperative Work in Design. pp 719-724

29. Zhang S, Xia X (2009) A new energy calculation model of belt conveyor. IEEE Africon 2009, Nairobi, Kenya. pp 23-25 